Article

\title{
Experimental and Computational Analyses of Temperature Distributions in Slope-Type Thin-Film Thermoelectric Generators at Different Slope Angles and Evaluation of Their Thermoelectric Performance
}

\author{
Saburo Tanaka ${ }^{1}$, Masaki Yamaguchi ${ }^{2}$, Rikuo Eguchi ${ }^{2}$ and Masayuki Takashiri ${ }^{2, *}$ \\ 1 Department of Mechanical Engineering, College of Engineering, Nihon University, 1 Nakagawara, Tokusada, \\ Tamuramachi, Koriyama, Fukushima 963-8642, Japan; tanaka.saburo@nihon-u.ac.jp \\ 2 Department of Materials Science, Tokai University, 4-1-1 Kitakaname, Hiratsuka, Kanagawa 259-1292, Japan; \\ 8bajm043@mail.u-tokai.ac.jp (M.Y.); 6ber1127@mail.u-tokai.ac.jp (R.E.) \\ * Correspondence: takashiri@tokai-u.jp
}

Received: 4 February 2020; Accepted: 25 February 2020; Published: 28 February 2020

\begin{abstract}
Thin-film thermoelectric generators are not widely used mainly because it is difficult to provide a temperature difference $(\Delta T)$ within the generators. To solve this problem, in our previous study, we prepared slope-type thin-film thermoelectric generators (STTEGs) using electrodeposition and transferred processes. A thin-film generator including n-type $\mathrm{Bi}_{2} \mathrm{Te}_{3}$ and p-type $\mathrm{Sb}_{2} \mathrm{Te}_{3}$ thin films was attached on slope blocks made of polydimethylsiloxane. In this study, the slope angle of STTEGs was optimized based on experimental results and computational analyses using computational fluid dynamics (CFD). With the increase in the slope angle, the $\Delta T$ began increasing and became saturated at a slope angle of $58^{\circ}$, and this trend was also confirmed by experimental measurements. When the heat source temperature was set at $65^{\circ} \mathrm{C}$, the $\Delta T$ computationally reached $26 \mathrm{~K}$ at a slope angle of $58^{\circ}$, and the maximum output power was $46.1 \mathrm{nW}$. Therefore, we demonstrated that the highest performance of STTEGs with an optimal slope angle can be estimated by combining the experimental results and computational analyses.
\end{abstract}

Keywords: electrodeposition; transfer process; slope-type thin-film thermoelectric generators; slope angle; computational fluid dynamics

\section{Introduction}

Thermoelectric generators are increasingly being viewed as promising energy harvesting devices due to the significant increase in awareness surrounding environmental protection and energy conservation [1-3]. This is because thermoelectric generators directly convert thermal energy to electrical energy, with no moving parts, while producing a low amount of noise. Thermoelectric generators contain several p-type and n-type semiconductor couples connected using metal electrodes. Electrical power is generated by the temperature difference between the two sides of the generator. The applications of thermoelectric generators, such as in automobiles, stoves, and industrial power plants, have prominently increased in the recent past [4-7]. Furthermore, with the advancement in Internet of Things (IoT) technology, the focus on miniaturizing thermoelectric generators has increased due to the extensive use of power sources for portable/mobile electronic devices and sensor network nodes [8-11].

There are two main types of thermoelectric generators, namely bulk- and thin-film thermoelectric generators. In bulk thermoelectric generators, block-like sintered thermoelectric legs of p-type and n-type semiconductors are connected using metal electrodes, and they are sandwiched between 
two insulating rigid substrates [12-15]. Due to their relatively large size and high output power, bulk thermoelectric generators are mainly used in automobiles, stoves, and industrial power plants, as mentioned above. Conversely, in the structure of thin-film thermoelectric generators, strip-like thermoelectric legs of p-type and n-type semiconductors are connected with thin metal electrodes and are patterned on an insulating substrate [16-19]. Moreover, thin-film thermoelectric generators can be formed on flexible substrates [20-23]. Although they cannot easily produce a large amount of output power, it is possible to install them in almost any place, including bent and narrow spaces. Therefore, thin-film thermoelectric generators may be used as power sources in portable and mobile electronic devices and sensor network nodes.

In thermoelectric materials, bismuth-telluride-based alloys are the most favorable materials for IoT applications because they exhibit the highest thermoelectric performance near $300 \mathrm{~K}$ [24-26]. Therefore, although bismuth-telluride-based alloys were developed in the 1950s [27,28], they are still being actively researched [29-32].

In the performance of thermoelectric generators, the energy conversion efficiency $\eta$ is expressed using Equation (1) [33]:

$$
\eta=\eta_{c} \frac{\sqrt{1+Z T_{M}}-1}{\sqrt{1+Z T_{M}+T_{c} / T_{h}}}
$$

where $\eta_{c}$ is the Carnot efficiency, $T_{M}=\left(T_{h}+T_{c}\right) / 2$ is the mean temperature, and $T_{h}$ and $T_{c}$ denote the temperature of the hot and cold sides, respectively. $Z T_{M}$ is the dimensionless figure-of-merit, which is described as $Z T_{M}=\sigma S^{2} T_{M} / \kappa$, where $\sigma$ is the electrical conductivity, $S$ is the Seebeck coefficient, and $\kappa$ is the thermal conductivity. In addition, the power factor, defined as $\sigma S^{2}$, is occasionally used as an alternative to $Z T_{M}$ for the evaluation of material performance. Therefore, the conversion efficiency of the generators depends on $Z T_{M}$ as well as the cold and hot side temperatures, which are strongly influenced by the design of the generators.

In bulk thermoelectric generators, several researchers have investigated their design to efficiently create temperature differences in the generators based on experimental and computational approaches [34-37]. Conversely, the investigation of thin-film thermoelectric generators is not as active when compared to bulk thermoelectric generators even though they are expected to be used as power supplies in IoT applications. This is because it is difficult to create temperature differences in thin-film thermoelectric generators. In order to overcome these drawbacks, various proposals to prepare thin-film generators, using experimental approaches in which the heat transfers along the surface direction of the thermoelectric (TE) legs, are in progress [38-40]. However, the computational approach to optimizing the design of thin-film thermoelectric generators is very limited.

In our previous studies, we fabricated a slope-type thin-film generator (STTEG) [41], and temperature differences were produced in the STTEG by placing them on a lower thermal conductive material by tilting them towards a heat source [42]. To optimize the design of STTEGs with high performance, it is necessary to evaluate the temperature distribution in the STTEGs over a wide range of setting conditions. In this study, based on our experimental measurement of STTEGs' temperature, the temperature distribution in STTEGs is calculated when they are put on a heat source with changing slope angles. The computations on a steady three-dimensional model are performed with a finite volume method using computational fluid dynamics (CFD). Finally, the thermoelectric performances of STTEGs are evaluated by changing the slope angles, and the optimal slope angle is determined.

\section{Experimental Setup}

In this study, we used the STTEGs that were fabricated in our previous study [42]. In brief, n-type $\mathrm{Bi}_{2} \mathrm{Te}_{3}$ and p-type $\mathrm{Sb}_{2} \mathrm{Te}_{3}$ thin films were prepared on a stainless-steel substrate using potentiostatic electrodeposition and a standard three-electrode cell. Figure 1 shows the photographs of a typical STTEG with a slope angle of $18^{\circ}$. The STTEG mainly consists of two parts. In Figure 1a, the first part is a thin-film thermoelectric generator fabricated using electrodeposition and a transfer process [41]. 
The generator is composed of two pairs of n-type $\mathrm{Bi}_{2} \mathrm{Te}_{3}$ and p-type $\mathrm{Sb}_{2} \mathrm{Te}_{3}$ films with a length of $25 \mathrm{~mm}$ and a width of $6 \mathrm{~mm}$, and these films are connected with silver pastes. The thickness of both types of the thin films is approximately $1 \mu \mathrm{m}$. The properties of the $\mathrm{n}$ - and p-type thin films and the STTEG are presented in Table 1 [42]. The second part is a slope block made of polydimethylsiloxane (PDMS) using a three-dimensional printer (Figure 1b). The PDMS was selected as the material for making the slope block because it possesses a relatively low thermal conductivity $(0.18 \mathrm{~W} /(\mathrm{m} \cdot \mathrm{K}))$ and flexibility. Five types of slope blocks with rectangular-triangle shapes were prepared. The slope angle was varied from $8^{\circ}$ to $28^{\circ}$ by adjusting the height of the slope blocks while the depth and width of the slope blocks were fixed at $30 \mathrm{~mm}$ each. The thin-film thermoelectric generator was attached on the slope block using a heat conductive silicone grease and metal electrodes were connected to both the ends (Figure 1c). Note that the generator is detachable; the same generator can be assembled with five types of slope blocks at different slope angles.

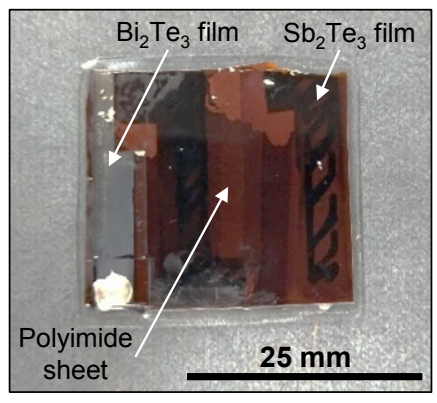

(a)

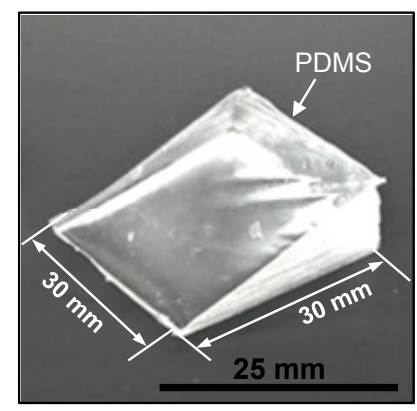

(b)

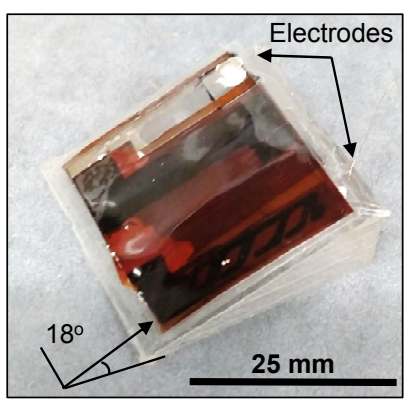

(c)

Figure 1. Photographs of a typical slope-type thin-film thermoelectric generator (STTEG) with a slope angle of $18^{\circ}$. (a) Thin film generator, (b) slope block, and (c) STTEG.

Table 1. Properties of $n$ - and $p$ - type thin films and the STTEG [42].

\begin{tabular}{ccccccc}
\hline & $\begin{array}{c}S \\
(\mu \mathbf{V} / \mathbf{K})\end{array}$ & $\begin{array}{c}\text { Thickness } \\
(\mu \mathbf{m})\end{array}$ & $\begin{array}{c}\boldsymbol{R}_{\boldsymbol{s}} \\
(\boldsymbol{\Omega} / \text { Square })\end{array}$ & $\begin{array}{c}\boldsymbol{R}_{\text {total }} \\
(\boldsymbol{\Omega})\end{array}$ & $\begin{array}{c}\boldsymbol{R}_{\text {film }} \\
(\boldsymbol{\Omega})\end{array}$ & $\begin{array}{c}\boldsymbol{R}_{\text {contact }} \\
(\boldsymbol{\Omega})\end{array}$ \\
\hline N-type film & -80 & 3.1 & 6 & - & - & - \\
P-type film & 100 & 4.1 & 12 & - & - & - \\
STTEG & - & - & - & 700 & 120 & 580 \\
\hline
\end{tabular}

\section{Computational Modeling}

To compute the temperature distribution in the STTEG by putting it on a heat source, a steady three-dimensional model based on CFD was employed. Figure 2 shows the schematic diagram of a STTEG system used for the calculations. Ideally, the thin-film thermoelectric generator should be attached on a PDMS slope. However, to simplify the model, the temperature distribution of only the PDMS slope was estimated without the thin-film thermoelectric generator because the volume and heat capacity of the PDMS slope were significantly larger than those of the thin-film thermoelectric generator. The heat and mass transfer in the models of the PDMS slope and air atmosphere were governed in a three-dimensional model expressing the conservation of mass, momentum, and energy. A turbulence model was used as a standard $k-\varepsilon$ model for compressible fluids. Region A (wall top) is the outlet of air. Region B (wall side) is the wall where air flows inwards and outwards. Region C (wall bottom) is the outlet of air. The temperature of the contact surface between Region D (wall PDMS) and Region E (wall Peltier) was constant at $65^{\circ} \mathrm{C}$, and the contact surface between PDMS and air was a stationary wall. The computations on the steady three-dimensional model with an unstructured grid were performed with a finite volume method using the commercial CFD-code SCRYU/Tetra V14. Table 2 presents the physical properties of the gas and material used in the calculations. The temperature distributions were calculated when the slope angle was varied from $8^{\circ}$ to $68^{\circ}$. 


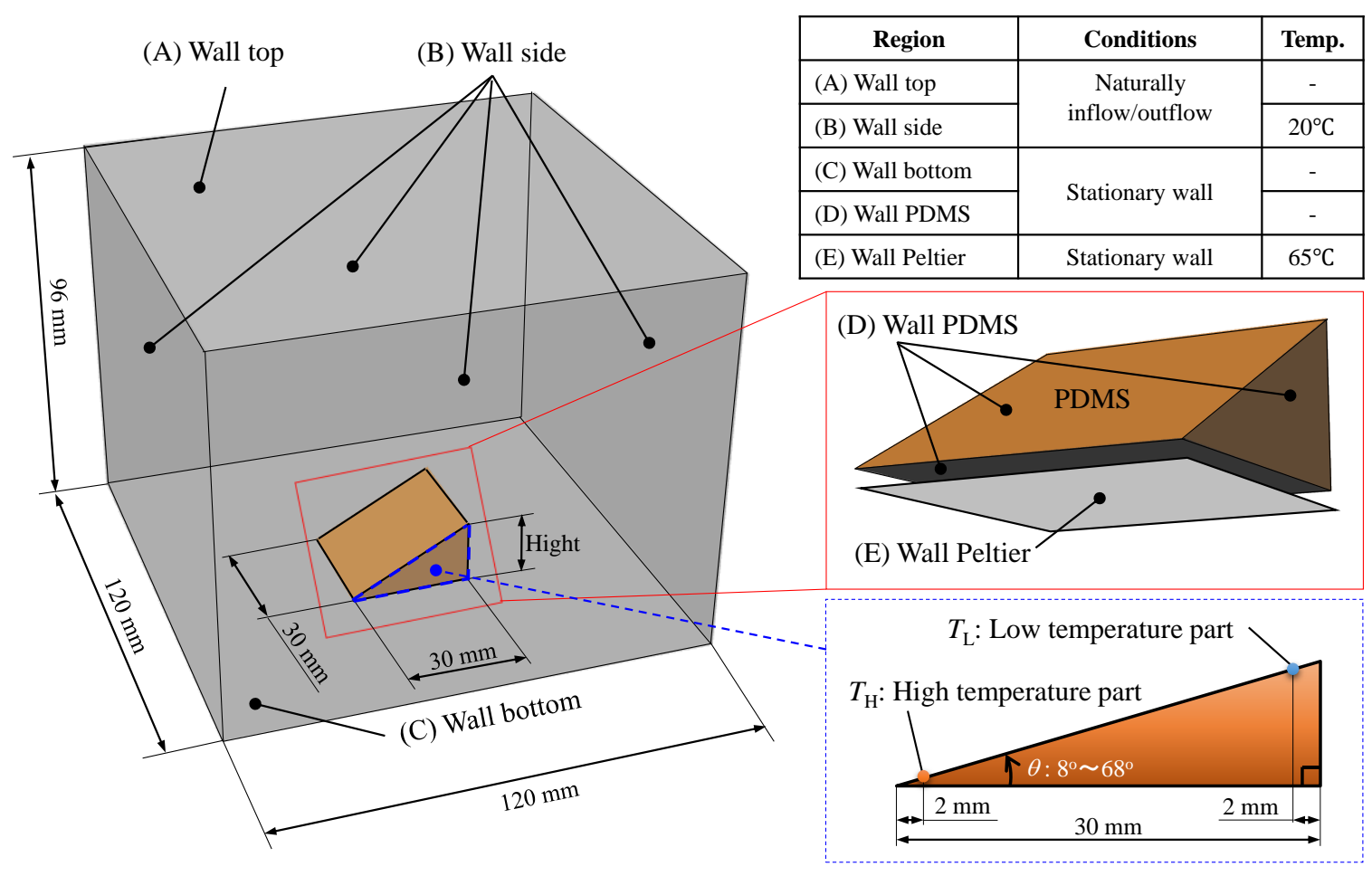

Figure 2. Analysis model of polydimethylsiloxane (PDMS) slope and analysis domain.

Table 2. Properties of gas and material.

\begin{tabular}{ccc}
\hline & Gas (Air) & PDMS \\
\hline Coefficient of value expansion $(1 / \mathrm{K})$ & 0.003411 & - \\
Density $\left(\mathrm{kg} / \mathrm{m}^{3}\right)$ & 1.206 & 1030 \\
Temperature $\left({ }^{\circ} \mathrm{C}\right)$ & 20 & - \\
Coefficient of viscosity $(\mathrm{Pa} \cdot \mathrm{s})$ & $1.83 \times 10^{-5}$ & - \\
Specific heat capacity $(\mathrm{J} /(\mathrm{kg} \cdot \mathrm{K}))$ & 1007 & 1100 \\
Thermal conductivity $(\mathrm{W} /(\mathrm{m} \cdot \mathrm{K}))$ & 0.0256 & 0.18 \\
\hline
\end{tabular}

\section{Results and Discussion}

\subsection{Temperature Distribution of STTEGs by Experimental Measurement}

To estimate the temperature distribution of the STTEG, it was put on the Peltier module, and the surface temperature of the Peltier module was maintained at $65{ }^{\circ} \mathrm{C}$. The temperatures of the STTEGs at hot and cold sides were measured using two K-type thermocouples. The measurement position on the hot side was $2 \mathrm{~mm}$ from the bottom center of the STTEG, and that on the cold side was $2 \mathrm{~mm}$ from the top center. Figure 3 shows the temperature differences between the hot and cold sides of the STTEGs at different slope angles. The time changes of temperature differences in the STTEGs are shown in Figure 3a. The STTEGs with all slope angles exhibited the largest temperature difference at $5 \mathrm{~min}$ because the heat flow did not sufficiently reach the cold side due to the low thermal conductivity of the PDMS. Thereafter, the temperature differences in the STTEGs with all slope angles decreased and saturated after $20 \mathrm{~min}$. Thus, we demonstrated that stable temperature differences were achieved in the STTEG system with all of the slope angles in this study. In Figure 3b, the relationship between the temperature difference and slope angle is presented. The temperature difference is the averaged value in the stable region from 20 to $60 \mathrm{~min}$. The temperature difference linearly increased with the slope angle. The deviation between the experimental results and linear fitting was approximately $\pm 6 \%$. The maximum temperature difference was $17 \mathrm{~K}$ at a slope angle of $28^{\circ}$. 


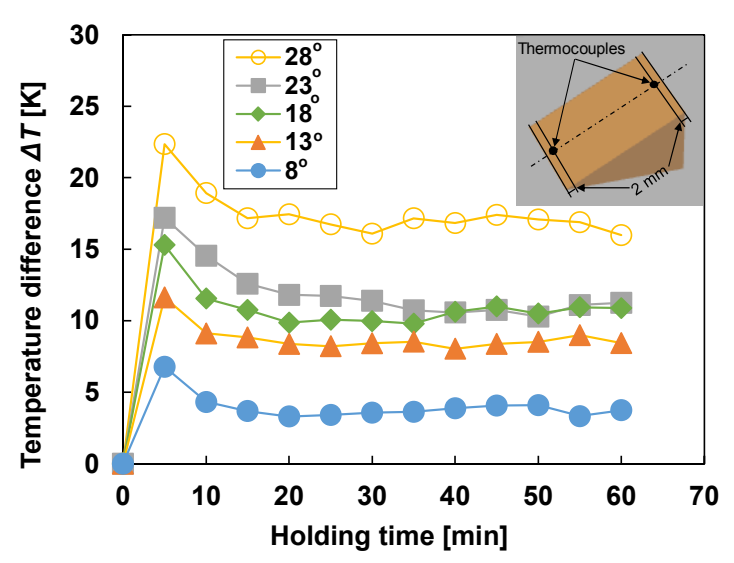

(a)

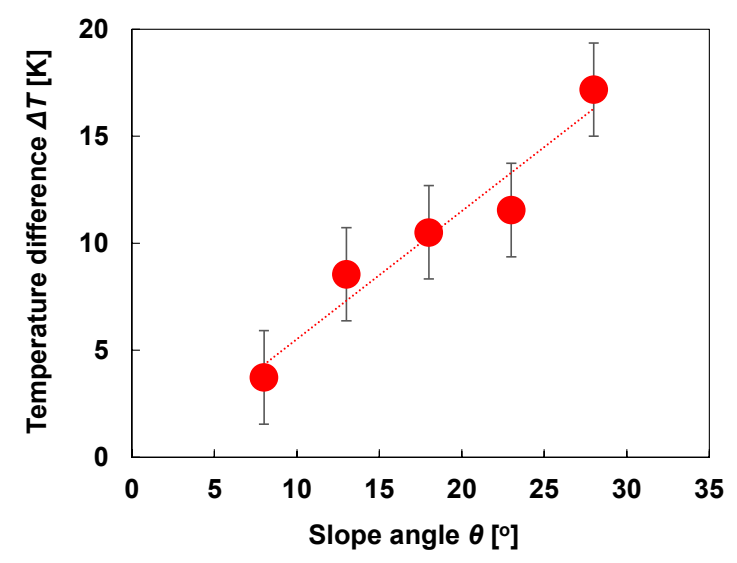

(b)

Figure 3. (a) Time change of temperature difference in STTEGs with different slope angles and (b) relationship between temperature difference and slope angle.

\subsection{Temperature Distribution of STTEGs by Numerical Analysis}

A typical result of a numerical analysis presenting the temperature distribution of the PDMS slope and the air velocity vector at a slope angle of $28^{\circ}$ is shown in Figure 4 . The surface color of the PDMS slope and arrow represents the temperature distribution and vector of flow velocity in the $\mathrm{x}$-axis section, respectively. The flow velocity tended to be faster above the top of the PDMS slope, indicating that heat dissipation occurred near the top of the slope. The surface temperature of the PDMS slope tended to decrease on increasing the distance from the heat source part (Region E in Figure 3). The temperature distributions on the surface of the PDMS slopes at different slope angles are shown in Figure 5a. At a slope angle of $8^{\circ}$, the area with the temperature over $60^{\circ} \mathrm{C}$ occupied the maximum slope surface. When the slope angle increased, an area with a lower temperature was seen near the top of the slope. No irregular temperature unevenness was observed for all of the slopes. In Figure $5 b$, the temperature differences observed in the computational analyses and the experimental measurements are compared with those in Figure $3 b$, where the temperature measurement positions were the same in both cases. The calculated temperature difference was approximately $16 \%$ higher than that obtained in the experimental measurements. This is possibly because the numerical analysis was performed under ideal conditions where air at a constant temperature was supplied into the analysis area. As a result, the cooling effect of the low-temperature part of PDMS was promoted by its steady natural convection, which was apparent in the model of the lower slope angle. The trends between the slope angle and the temperature difference were similar in both cases. Therefore, we concluded that a computational model that reproduced the experimental results was created.

Figure 6 shows the temperature differences in the PDMS slopes that were calculated at slope angles higher than $28^{\circ}$ using the created calculation model. According to the calculation results, the temperature difference $(\Delta T)$ increased linearly up to the slope angle of $40^{\circ}$ on increasing the slope angle, and then saturated at the slope angle of $58^{\circ}$. The appearance of this saturation can be explained as follows: when the thermal resistance increased on increasing the distance from the heat source to the cold side, the temperature of the cold side reached $20^{\circ} \mathrm{C}$ (ambient temperature) at a slope angle of $58^{\circ}$, as described in the inset of Figure 6. In order to evaluate the validity of the calculation results, a PDMS slope block with an angle of $58^{\circ}$ was fabricated, and then we measured the temperature difference. As a result, the experimentally measured temperature difference was $24 \mathrm{~K}$, which was only $8 \%$ lower than the calculated value at the corresponding angle. Therefore, we may conclude that the calculation model in this study obtained sufficient accuracy even though the slope angle was higher than $28^{\circ}$. 


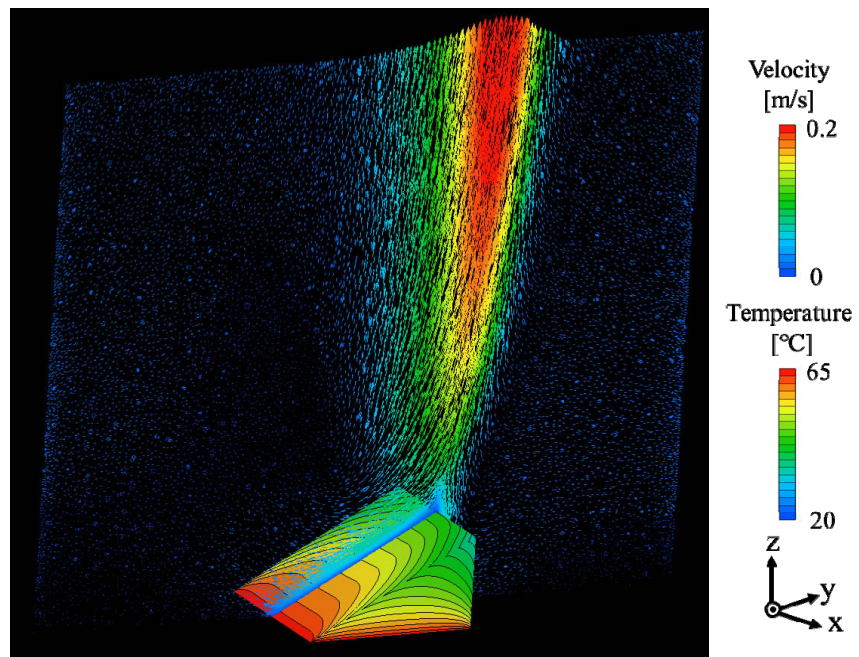

Figure 4. Temperature distribution of PDMS and the air velocity vector at a slope angle of $28^{\circ}$. The velocity vector and temperature of each color bar range from 0.0 to $0.2 \mathrm{~m} / \mathrm{s}$ and from 20 to $65^{\circ} \mathrm{C}$, respectively.

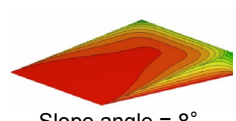

Slope angle $=8^{\circ}$

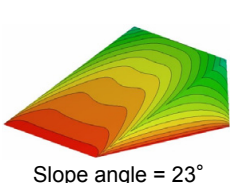

Slope angle $=23^{\circ}$
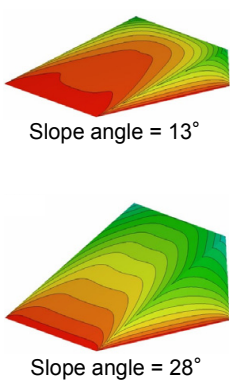

(a)
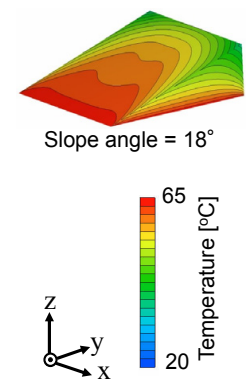

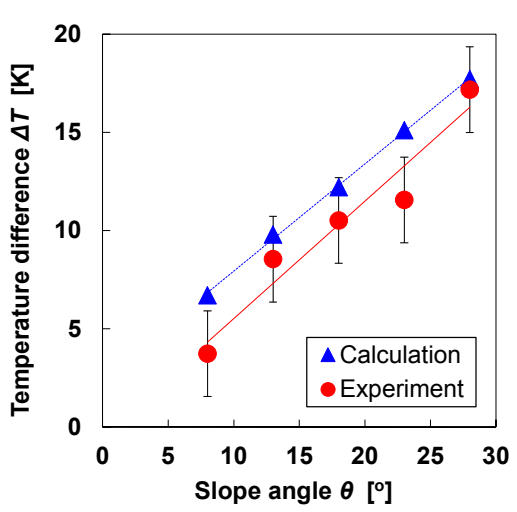

(b)

Figure 5. (a) Temperature distribution in the surface of PDMS slopes with different slope angles and (b) slope angle dependence on the temperature difference in the PDMS slope.

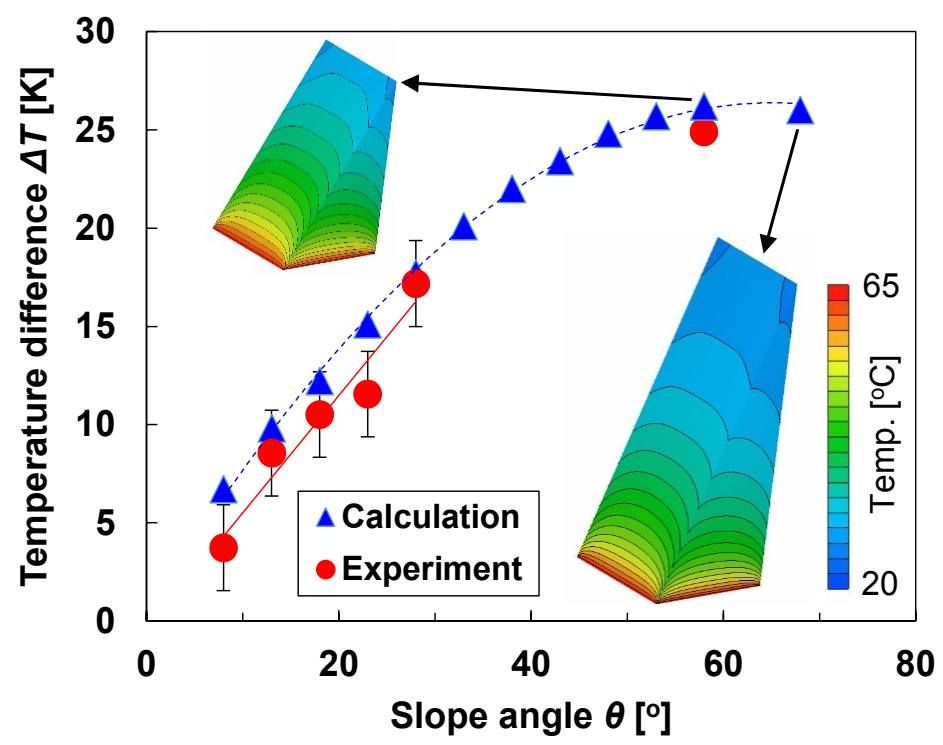

Figure 6. Calculated temperature difference in the PDMS slope at higher slope angles. 


\subsection{Thermoelectric Performance of STTEGs}

Figure 7 shows the thermoelectric performance of STTEGs as a function of slope angle. In this study, we assumed that the length of the STTEGs increased as the slope angle was increased. This is because the length of the slope increased as the slope angle increased, as described in the inset of Figure 6. The relationship between the open circuit voltage $\left(V_{o c}\right)$ and the slope angle is shown in Figure 7a. The $V_{o c}$ is independent of the length of the STTEGs. The experimentally measured $V_{o c}$ is presented from $8^{\circ}$ to $28^{\circ}$. In this range of angles, the measured $V_{o c}$ linearly increased as the slope angle increased. The maximum measured $V_{o c}$ was $8.1 \mathrm{mV}$ at the slope angle of $28^{\circ}$. Based on the measured values, the $V_{o c}$ was calculated at the angles from $8^{\circ}$ to $68^{\circ}$. For higher slope angles, we did not calculate $V_{o c}$ because the temperature difference became saturated, as shown in Figure 6. The values of $V_{o c} / \Delta T$ using the experimentally measured $V_{o c}$ and $\Delta T$ were estimated at five angles from $8^{\circ}$ to $28^{\circ}$. The five values of $V_{o c} / \Delta T$ were then averaged, and the $V_{o c}$ that was estimated based on the averaged $V_{o c} / \Delta T$ and the calculated $\Delta T$ is shown in Figure 6. We assumed that the thermoelectric properties of $\mathrm{p}$ - and n-type thin films were not changed in the entire region during this study. The average error between the experimental and theoretical values at the slope angles from $8^{\circ}$ to $28^{\circ}$ was approximately $20 \%$. When the slope angle was increased up to $28^{\circ}$, the $V_{o c}$ increased and then became saturated at slope angles higher than $58^{\circ}$. The calculated maximum $V_{o c}$ was $12.2 \mathrm{mV}$ at the angle of $58^{\circ}$. Therefore, when the heat source temperature was set at $65^{\circ} \mathrm{C}$, STTEGs can produce the $V_{o c}$ of $12.2 \mathrm{mV}$ by optimizing the slope angle. To further increase the $V_{o c}$, it is necessary to increase the number of $\mathrm{p}-\mathrm{n}$ pairs of thin films.

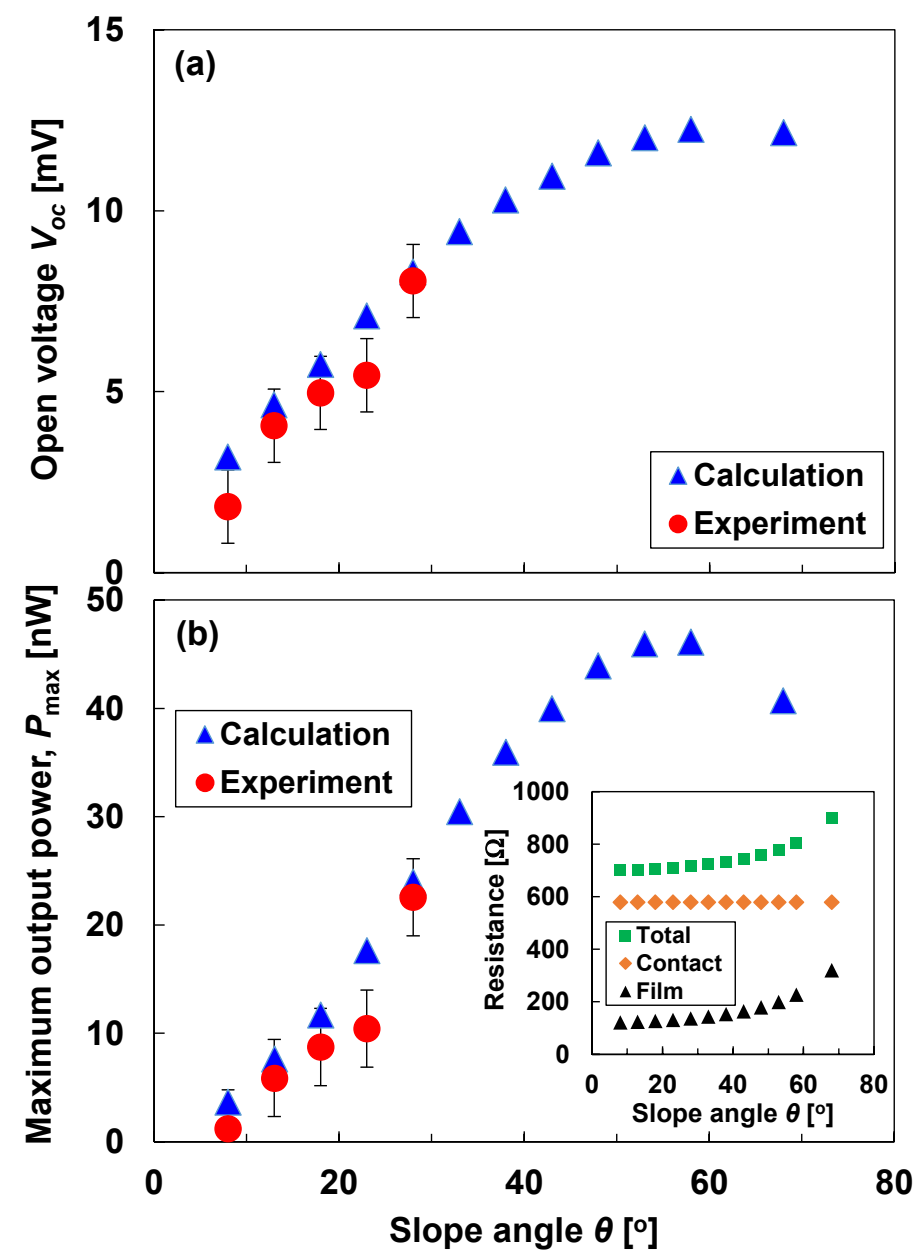

Figure 7. Thermoelectric performance of STTEGs as a function of slope angle. (a) Open circuit voltage and (b) maximum output power. 
The relationship between the slope angle and the maximum output power $\left(P_{\max }\right)$ is presented in Figure $7 \mathrm{~b}$. The $P_{\max }$ is expressed as $P_{\max }=V_{o c}{ }^{2} / 4 R_{\text {total }}$, where $R_{\text {total }}$ is the total resistance of the STTEG, including the resistance of the thin film and contact resistance. The measured $R_{\text {total }}$ was $700 \Omega$, which is the sum of $580 \Omega$ from the film resistance and $120 \Omega$ from the contact resistance, as presented in Table 1. We assumed that the $R_{\text {total }}$ varied as the slope angle increased because the resistance of the films increased due to the increase in the film's length while the contact resistance was constant, as shown in the inset of Figure $7 \mathrm{~b}$. The experimentally measured $P_{\max }$ values were between $8^{\circ}$ and $28^{\circ}$, and the highest measured $P_{\max }$ was $22.6 \mathrm{nW}$ at a slope of $28^{\circ}$. This $P_{\max }$ was insufficient to drive the various sensors. For example, sensors for ammonia vapor in ambient air require an electrical power of approximately $50 \mathrm{nW}$ [43]. The comparison of the experimental and theoretical results shows a similar trend for the slope angle's dependence of $P_{\max }$. When the slope angle was increased above $28^{\circ}$, the $P_{\max }$ increased and then peaked at the slope angle of $58^{\circ}$. The calculated value of $P_{\max }$ was $46.1 \mathrm{nW}$ at an angle of $58^{\circ}$. This value is approximately 2 times higher than the highest value of the experimental results, and was close to the power that could drive ammonia vapor sensors [43]. For further increases in the slope angle, the value of $P_{\max }$ decreased because the resistance of the STTEG increased but the temperature difference was comparable to that at $58^{\circ}$. Therefore, we can efficiently estimate the maximum performance of an STTEG with an optimal slope angle by combining a small number of experimental results and the calculated temperatures of the STTEGs by CFD. To further improve the performance of STTEGs, reliable approaches, such as an increase in film thickness, as well as a decrease in contact resistance, are required.

\section{Conclusions}

STTEGs were prepared with slope angles from $8^{\circ}$ to $28^{\circ}$. When the heat source temperature was maintained at $65^{\circ} \mathrm{C}$, the highest thermoelectric performance of the STTEG was $V_{o c}=12.2 \mathrm{mV}$ and $P_{\max }=22.6 \mathrm{nW}$ at the slope angle of $28^{\circ}$. To investigate the potential performance of the STTEG, the temperature distribution in the STTEGs was calculated using CFD at slope angles above $28^{\circ}$ based on the experimentally measured temperatures. It was found that the temperature difference between the cold and hot sides reached $26 \mathrm{~K}$ at a slope angle of $58^{\circ}$, and the temperature difference was almost constant upon further increasing the slope angle. As a result, the STTEGs achieved a $P_{\max }$ of $46.1 \mathrm{nW}$, which was approximately 2 times higher than the highest value obtained through experimentation. However, this result was still lower than the value of thin-film generators with a large number of $p-n$ pairs [17]. Therefore, to further improve the performance of STTEGs, we plan to increase the number of $\mathrm{p}-\mathrm{n}$ pairs while the contact resistance is minimized.

Author Contributions: M.T. proposed this research; S.T. prepared the calculation model; M.Y. and R.E. performed the experiments and analyzed the data; and S.T. and M.T. wrote the manuscript. All authors have read and agreed to the published version of the manuscript.

Funding: This research received no external funding.

Acknowledgments: This work was partially supported by the Tokai University General Research Organization Grant. The authors wish to thank Kuwahata, H. Yamamuro, and T. Chiba at Tokai University for providing support during experimentation.

Conflicts of Interest: The authors declare no conflicts of interest.

\section{References}

1. Hsu, C.-T.; Huang, G.-Y.; Chu, H.-S.; Yu, B.; Yao, D.-J. Experiments and simulations on low-temperature waste heat harvesting system by thermoelectric power generators. Appl. Energy 2011, 88, 1291-1297. [CrossRef]

2. Kishita, Y.; Ohishi, Y.; Uwasu, M.; Kuroda, M.; Takeda, H.; Hara, K. Evaluating the life cycle $\mathrm{CO}_{2}$ emissions and costs of thermoelectric generators for passenger automobiles: a scenario analysis. J. Clean. Prod. 2016, 126, 607-619. [CrossRef]

3. Tahami, S.A.; Gholikhani, M.; Nasouri, R.; Dessouky, S.; Papagiannakis, A.T. Developing a new thermoelectric approach for energy harvesting from asphalt pavements. Appl. Energy 2019, 238, 786-795. [CrossRef] 
4. Champier, D. Thermoelectric generators: A review of applications. Energy Convers. Manag. 2017, 140, 167-181. [CrossRef]

5. Yang, J.; Stabler, F.R. Automotive applications of thermoelectric materials. J. Electron. Mater. 2009, 38, 1245-1251. [CrossRef]

6. Champier, D.; Bédécarrats, J.P.; Kousksou, T.; Rivaletto, M.; Strub, F.; Pignolet, P. Study of a TE (thermoelectric) generator incorporated in a multifunction wood stove. Energy 2011, 36, 1518-1526. [CrossRef]

7. Date, A.; Date, A.; Dixon, C.; Akbarzadeh, A. Progress of thermoelectric power generation systems: prospect for small to medium scale power generation. Renew. Sustain. Energy Rev. 2014, 33, 371-381. [CrossRef]

8. Paradiso, J.A.; Starner, T. Energy scavenging for mobile and wireless electronics. IEEE Pervasive Comput. 2005, 4, 18-27. [CrossRef]

9. Vullers, R.J.M.; van Schaijk, R.; Doms, I.; Van Hoof, C.; Mertens, R. Micropower energy harvesting. Solid State Electron 2009, 53, 684-693. [CrossRef]

10. Siddique, A.R.M.; Mahmud, S.; Van Heyst, B. A review of the state of the science on wearable thermoelectric power generators (TEGs) and their existing challenges. Renew. Sustain. Energy Rev. 2017, 73, 730-744. [CrossRef]

11. Iezzi, B.; Ankireddy, K.; Twiddy, J.; Losego, M.D.; Jur, J.S. Printed, metallic thermoelectric generators integrated with pipe insulation for powering wireless sensors. Appl. Energy 2017, 208, 758-765. [CrossRef]

12. Slack, G.A.; Hussain, M.A. The maximum possible conversion efficiency of silicon-germanium thermoelectric generators. J. Appl. Phys. 1991, 70, 2694-2718. [CrossRef]

13. Rauscher, L.; Fujimoto, S.; Kaibe, H.T.; Sano, S. Efficiency determination and general characterization of thermoelectric generators using an absolute measurement of the heat flow. Meas. Sci. Technol. 2005, 16, 1054-1059. [CrossRef]

14. Kuroki, T.; Kabeya, K.; Kazuya, T.; Kajihara, M.; Kaibe, H.; Hachiuma, H.; Matsuno, H.; Fujibayashi, A. Thermoelectric generation using waste heat in steel works. J. Electron. Mater. 2014, 43, 2405-2410. [CrossRef]

15. Suzuki, R.O.; Sasaki, Y.; Fujisaka, T.; Chen, M. Effects of fluid directions on heat exchange in thermoelectric generators. J. Electron. Mater. 2012, 41, 1766-1770. [CrossRef]

16. Carmo, J.P.; Ribeiro, J.F.; Silva, M.F.; Goncalves, L.M.; Correia, J.H. Thermoelectric generator and solid-state battery for stand-alone microsystems. J. Micromech. Microeng. 2010, 20, 085033. [CrossRef]

17. Boniche, I.; Masilamani, S.; Durscher, R.J.; Morgan, B.C.; Arnold, D.P. Design of a miniaturized thermoelectric generator using micromachined silicon substrates. J. Electron. Mater. 2009, 38, 1293-1302. [CrossRef]

18. Takashiri, M.; Shirakawa, T.; Miyazaki, K.; Tsukamoto, H. Fabrication and characterization of bismuth-telluride-based alloy thin film thermoelectric generators by a flash evaporation method. Sens. Actuators A 2007, 138, 329-334. [CrossRef]

19. Takayama, K.; Takashiri, M. Multi-layered-stack thermoelectric generators using p-type $\mathrm{Sb}_{2} \mathrm{Te}_{3}$ and n-type $\mathrm{Bi}_{2} \mathrm{Te}_{3}$ thin films by radio-frequency magnetron sputtering. Vacuum 2017, 144, 164-171. [CrossRef]

20. Hamada, J.; Yamamoto, K.; Takashiri, M. Fabrication and characterization of roll-type thin-film thermoelectric generators. J. Phys. Conf. Ser. 2018, 1052, 012129. [CrossRef]

21. Suemori, K.; Hoshino, S.; Kamata, T. Flexible and lightweight thermoelectric generators composed of carbon nanotube-polystyrene composites printed on film substrate. Appl. Phys. Lett. 2013, 103, 153902. [CrossRef]

22. Shen, S.; Zhu, W.; Deng, Y.; Zhao, H.; Peng, Y.; Wang, C. Enhancing thermoelectric properties of $\mathrm{Sb}_{2} \mathrm{Te}_{3}$ flexible thin film through microstructure control and crystal preferential orientation engineering. Appl. Surf. Sci. 2017, 414, 197-204. [CrossRef]

23. Morgan, K.A.; Tang, T.; Zeimpekis, I.; Ravagli, A.; Craig, C.; Yao, J.; Feng, Z.; Yarmolich, D.; Barker, C.; Assender, H.; et al. High-throughput physical vapors deposition flexible thermoelectric generators. Sci. Rep. 2019, 9, 4393. [CrossRef] [PubMed]

24. Venkatasubramanian, R.; Siivola, E.; Colpitts, T.; O'Quinn, B. Thin-film thermoelectric devices with high room-temperature figures of merit. Nature 2001, 413, 597-602. [CrossRef] [PubMed]

25. Poudel, B.; Hao, Q.; Ma, Y.; Lan, Y.; Minnich, A.; Yu, B.; Yan, X.; Wang, D.; Muto, A.; Vashaee, D.; et al. High-thermoelectric performance of nanostructured bismuth antimony telluride bulk alloys. Science 2008, 320, 634-638. [CrossRef]

26. Yamauchi, K.; Takashiri, M. Highly oriented crystal growth of nanocrystalline bismuth telluride thin films with anisotropic thermoelectric properties using two-step treatment. J. Alloys Compd. 2017, 698, 977-983. [CrossRef] 
27. Harman, T.C.; Paris, B.; Miller, S.E.; Goering, H.L. Preparation and some physical properties of $\mathrm{Bi}_{2} \mathrm{Te}_{3}, \mathrm{Sb}_{2} \mathrm{Te}_{3}$, and $\mathrm{As}_{2} \mathrm{Te}_{3}$. J. Phys. Chem. Solids 1957, 3, 181-190. [CrossRef]

28. Goldsmid, H.J.; Douglas, R.W. The use of semiconductors in thermoelectric refrigeration. Br. J. Appl. Phys. 1954, 5, 386-390.

29. Khumtong, T.; Sukwisute, P.; Sakulkalavek, A.; Sakdanuphab, R. Microstructure and electrical properties of antimony telluride thin films deposited by rf magnetron sputtering on flexible substrate using different sputtering pressures. J. Electron. Mater. 2017, 46, 3166-3171. [CrossRef]

30. Mizoshiri, M.; Mikami, M.; Ozaki, K.; Shikida, M.; Hata, S. Lift-off patterning of thermoelectric thick films deposited by a thermally assisted sputtering method. Appl. Phys. Express 2014, 7, 057101. [CrossRef]

31. Takashiri, M.; Hamada, J. Bismuth antimony telluride thin films with unique crystal orientation by two-step method. J. Alloys Compd. 2016, 683, 276-281. [CrossRef]

32. Kudo, S.; Tanaka, S.; Miyazaki, K.; Nishi, Y.; Takashiri, M. Anisotropic analysis of nanocrystalline bismuth telluride thin films treated by homogeneous electron beam irradiation. Mater. Trans. 2017, 58, 513-519. [CrossRef]

33. Goldsmid, H.J. CRC handbook of thermoelectrics. In Conversion Efficiency and Figure-of-Merit; Rowe, D.M., Ed.; CRC Press: New York, NY, USA, 1995; pp. 19-42.

34. Suzuki, R.O.; Tanaka, D. Mathematical simulation of thermoelectric power generation with the multi-panels. J. Power Sources 2003, 122, 201-209. [CrossRef]

35. Wang, F.; Zhou, J.; Wang, G.; Zhou, X. Simulation on thermoelectric device with hydrogen catalytic combustion. Int. J. Hydrogen Energy 2012, 37, 884-888. [CrossRef]

36. Chen, M.; Rosendahl, L.A.; Condra, T. A three-dimensional numerical model of thermoelectric generators in fluid power systems. Int. J. Heat Mass Transfer 2011, 54, 345-355. [CrossRef]

37. He, H.; Liu, W.; Wu, Y.; Rong, M.; Zhao, P.; Tang, X. An approximate and efficient characterization method for temperature-dependent parameters of thermoelectric modules. Energy Convers. Manage. 2019, 180, 584-597. [CrossRef]

38. Wang, W.; Ji, Y.; Xu, H.; Li, H.; Visan, T.; Golgovici, F. A high packing density micro-thermoelectric power generator based on film thermoelectric materials fabricated by electrodeposition technology. Surf. Coat. Technol. 2013, 231, 583-589. [CrossRef]

39. Ito, Y.; Mizoshiri, M.; Mikami, M.; Kondo, T.; Sakurai, J.; Hata, S. Fabrication of thin-film thermoelectric generators with ball lenses for conversion of near-infrared solar light. Jpn. J. Appl. Phys. 2017, 56, 06GN06. [CrossRef]

40. Kurosaki, J.; Yamamoto, A.; Tanaka, S.; Cannon, J.; Miyazaki, K.; Tsukamoto, H. Fabrication and evaluation of a thermoelectric microdevice on a free-standing substrate. J. Electron. Mater. 2009, 38, 1326-1330. [CrossRef]

41. Yamamuro, H.; Hatsuta, N.; Wachi, M.; Takei, Y.; Takashiri, M. Combination of electrodeposition and transfer processes for flexible thin-film thermoelectric generators. Coatings 2018, 8, 22. [CrossRef]

42. Yamamuro, H.; Takashiri, M. Power generation in slope-type thin-film thermoelectric generators by the simple contact of a heat source. Coatings 2019, 9, 63. [CrossRef]

43. Feng, L.; Tang, W.; Zhao, J.; Yang, R.; Hu, W.; Li, Q.; Wang, R.; Guo, X. Unencapsulated air-stable organic field effect transistor by all solution processes for low power vapor sensing. Sci. Rep. 2016, 6, 20671. [CrossRef] [PubMed]

(C) 2020 by the authors. Licensee MDPI, Basel, Switzerland. This article is an open access article distributed under the terms and conditions of the Creative Commons Attribution (CC BY) license (http://creativecommons.org/licenses/by/4.0/). 